\title{
Carotenóides como alternativa contra a hipovitaminose $\mathrm{A}$
}

\section{Carotenoids as an alternative against hypovitaminosis A}

\section{RE S U M O}

A hipovitaminose A acarreta xeroftalmia, cegueira e morte em milhares de crianças no mundo e constitui um dos principais problemas nutricionais de populações de países em desenvolvimento, incluído o Brasil. Embora haja grande disponibilidade de frutas e verduras, fontes de carotenóides no Brasil, a hipovitaminose A constitui um grave problema de saúde pública. A falta de informação da população, no que diz respeito às fontes alimentares e aos fatores que interferem na biodisponibilidade dos carotenóides, citados na literatura, com a "mnemônica" SLAMENGHI são possíveis causas associadas a esta contradição. Os atuais fatores de conversão de carotenóides em retinol são superiores aos antigos fatores, o que pressupõe uma efetividade ainda menor na conversão dos carotenóides na forma ativa da vitamina A e coloca em questão a utilização destes no combate à hipovitaminose A. Esta revisão tem como objetivo relatar o que vem sendo abordado acerca do tema biodisponibilidade e fontes de carotenóides, para possibilitar um melhor posicionamento na utilização dos carotenóides no combate à hipovitaminose $A$.

Termos de indexação: carotenóides; disponibilidade biológica; hipovitaminose A.

\section{A B S T R A C T}

Hypovitaminosis A causes xerophthalmia, blindness and death in thousands of children throughout the world and constitutes one of the main nutritional problems in the populations of developing countries, including Brazil. Although fruits and vegetables, sources of carotenoids, are widely available in Brazil, hypovitaminosis A constitutes a serious public health problem. The lack of information available to the population about the dietary sources of carotenoids and factors affecting their bioavailability, known in the literature as SLAMENGHI, are possible causes associated with this contradiction. Current carotenoid conversion factors to retinol are higher than earlier ones. This suggests a reduced effectiveness in the conversion of carotenoids into the active form of vitamin A, questioning the role of carotenoids in combating hypovitaminosis $A$. The aim of this review is to discuss the bioavailability of carotenoids and their food sources in order to better assess the possibility of using these pigments to combat hypovitaminosis $A$.

Indexing terms: carotenoids; biological vailability; hypovitaminosis A.

\footnotetext{
1 Doutoranda, Curso de Pós-Graduação em Nutrição, Departamento de Nutrição, Laboratório de Bioquímica da Nutrição, Universidade Federal de Pernambuco. Cidade Universitária, 50670-901, Recife, PE, Brasil. Correspondência para/Correspondence to: C.L.B.A.AMBRÓSIO.E-mail: <cburgos@nutricao.ufpe.br>

2 Departamento de Nutrição, Universidade Federal de Pernambuco. Recife, PE, Brasil.
} 


\section{N T R O D U Ç Ã O}

A vitamina A é importante para o crescimento, desenvolvimento, manutenção de tecidos epiteliais, reprodução, sistema imunológico e, em especial, para o funcionamento do ciclo visual na regeneração de fotorreceptores ${ }^{1}$.

A hipovitaminose A acarreta xeroftalmia, cegueira e morte em milhares de crianças no mundo e constitui um dos principais problemas nutricionais de populações de países em desenvolvimento, incluído o Brasil. Ramalho et al. ${ }^{2}$, identificaram que em todas as regiões brasileiras para as quais existem dados, foi constatada a carência marginal de vitamina $A$, com alta prevalência em diferentes faixas etárias.

Em decorrência do alto custo dos alimentos de origem animal, as provitaminas vegetais constituem a maior porção das vitaminas dietéticas, podendo chegar a 88\% nos países em desenvolvimento, segundo a World Health Organization (WHO) ${ }^{3}$. Embora haja grande disponibilidade de frutas e verduras fontes de carotenóides no Brasil, existe, em contradição, um elevado número de crianças com hipovitaminose A. A falta de informação da população no que diz respeito às fontes alimentares, associada aos fatores que interferem na biodisponibilidade dos

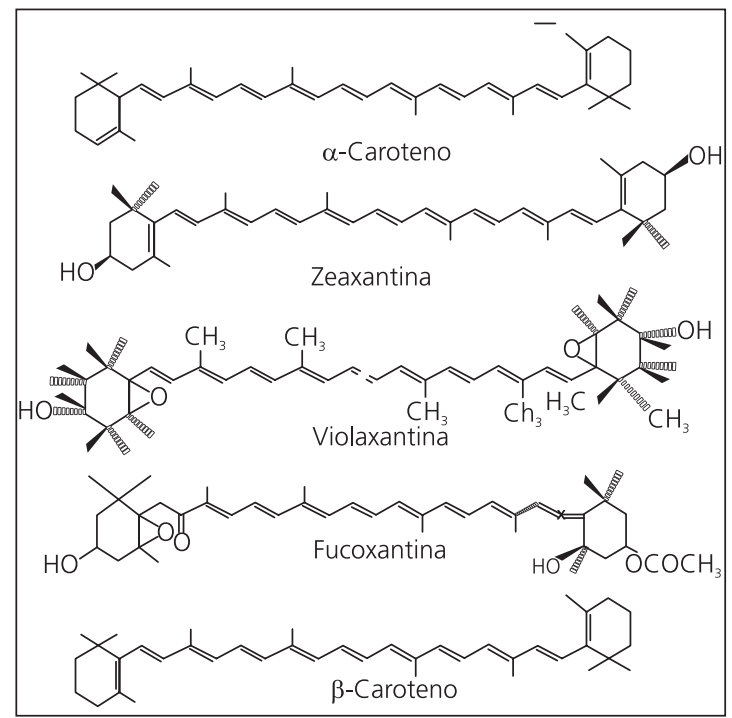

carotenóides, citados na literatura com a "mnemônica" SLAMENGHI", são possíveis fatores associados a esta contradição.

Pesquisas ${ }^{5,6}$ sugerem que os atuais fatores de conversão da vitamina $A$ são atividade equivalente de retinol $(R A E)$, no qual $1 \mu \mathrm{g} R A E=$ Unidades comumente tilizadas; $1 \mathrm{RE}$ de retinol (vitamina $A$ ); $1 \mu$ g retinol (vitamina $A$ ); $2 \mu \mathrm{g} \beta$-caroteno em óleo; $12 \mu \mathrm{g}$ de $\beta$-caroteno em mistura de alimentos; $24 \mu \mathrm{g}$ de outros carotenóides (precursores de vitamina A) em mistura de alimentos.

Os atuais fatores de conversão são superiores às antigas recomendações ( $1 \mathrm{RE}=1 \mu \mathrm{g}$ retinol/ $6 \mu \mathrm{g}$ de $\beta$-caroteno/ $12 \mu \mathrm{g}$ de outros carotenóides precursores de vitamina A) (NAS/NRC), o que implica uma efetividade ainda menor na conversão do $\beta$-caroteno em retinol, fato este que motivou a realização desta revisão que se propõe a expor o que vem sendo abordado acerca do tema ${ }^{7}$.

\section{Carotenóides}

Os carotenóides (Figura 1) são geralmente tetraterpenóides de 40 átomos de carbono, de coloração amarela, laranja ou vermelha. São encontrados em vegetais e classificam-se em carotenos ou xantofilas. Os carotenos são

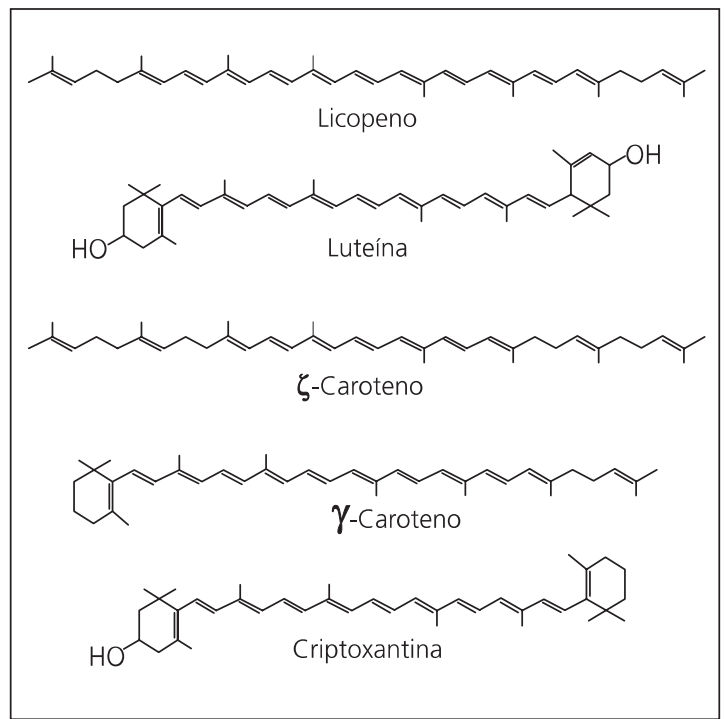

Figura 1. Estrutura química de alguns carotenóides. 
hidrocarbonetos poliênicos com variados graus de insaturação, e as xantofilas são sintetizadas a partir dos carotenos, por meio de reações de hidroxilação e epoxidação. O $\beta$-caroteno e o licopeno são exemplos de carotenos, enquanto a luteína e a zeaxantina são xantofilas.

Em decorrência da presença das insaturações, os carotenóides são sensíveis à luz, temperatura, acidez, bem como reações de oxidação. São compostos hidrofóbicos, lipofílicos, insolúveis em água e solúveis em solventes, como acetona, álcool e clorofórmio.

Dos mais de 600 carotenóides conhecidos, aproximadamente 50 são precursores da vitamina A. O carotenóide precursor possui pelo menos um anel de $\beta$-ionona não substituído, com cadeia lateral poliênica com um mínimo de 11 carbonos. Entre os carotenóides, o $\beta$-caroteno é o mais abundante em alimentos e o que apresenta a maior atividade de vitamina A (Figura 2).

Tanto os carotenóides precursores de vitamina A como os não precursores, como a luteína, a zeaxantina e o licopeno, parecem apresentar ação protetora contra o câncer ${ }^{8,9}$, e os possíveis mecanismos de proteção são por intermédio do seqüestro de radicais livres, modulação do metabolismo do carcinoma, inibição da proliferação celular, aumento da diferenciação celular via retinóides, estimulação da comunicação entre as células e aumento da resposta imune ${ }^{10}$.

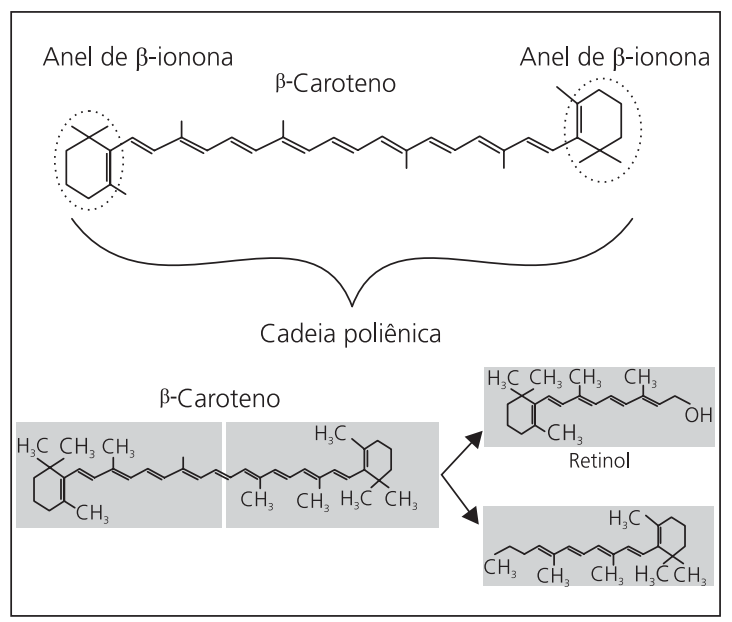

Figura 2. Estrutura química e clivagem do $\beta$-caroteno.
O $\beta$-caroteno é um potente antioxidante com ação protetora contra doenças cardiovasculares $^{11,12}$. A oxidação do LDL-colesterol é fator crucial para o desenvolvimento da aterosclerose e o $\beta$-caroteno atua inibindo o processo de oxidação da lipoproteína.

Estudos apontam que a luteína e a zeaxantina, que são amplamente encontradas em vegetais verde-escuros, parecem exercer uma ação protetora contra degeneração macular e catarata ${ }^{13,14}$.

\section{Absorção e transporte}

Os processos de absorção e transporte dos carotenóides são similares aos dos lipídios. Após ingeridos, os carotenóides são incorporados em micelas mistas constituídas de ácidos biliares, ácidos graxos livres, monoglicerídios e fosfolipídios. A absorção ocorre sem clivagem e em carotenóides como o $\beta$-caroteno e a criptoxantina, que são parcialmente convertidos a retinal, a hidrólise acontece no interior da célula intestinal. Posteriormente o retinal é convertido a retinol e transportado por meio dos vasos linfáticos ao fígado pelos quilomícrons, na forma de ésteres de retinol.

O fígado contém $90 \%$ da vitamina A do organismo. Aproximadamente $40 \%$ do retinol é prontamente utilizado, enquanto o restante permanece armazenado. No fígado, o retinol é liberado a partir do palmitato de retinol, por meio da ação de uma retinil-éster-hidrolase e, posteriormente, ou se liga à proteína de ligação ao retinol (PLR) plasmática para passar ao plasma ou é captado pela PLR citoplasmática e levado aos sítios de estocagem, que são os adipócitos e os hepatócitos.

O armazenamento na forma de éster de retinol é feito através da ação da retinol-acil-transferase sobre o retinol. Ao chegar no plasma, o complexo retinol-PLR se liga à pré-albumina que o protegerá da ação da degradação no rim. Após se ligar aos receptores de membrana, o retinol 
entra nos sítios celulares e a PLR volta à circulação para ser degradada e reciclada. Ao entrar na célula, o retinol se fixa a uma molécula de transporte citoplasmática, a proteína de ligação ao retinol (específica do órgão) que o transporta ao sítio de ação. Além disso o retinol pode ser oxidado e se transformar em ácido retinóico, que se liga a receptores nucleares específicos.

No que diz respeito ao processo de captação intestinal dos carotenóides, os fatores intracelulares ou do lúmen que limitam esse processo ainda não são bem esclarecidos.

A quantidade de carotenóides incorporada nas micelas depende da polaridade do carotenóide e da composição e saturação dos ácidos graxos micelares. Os carotenóides são transportados no plasma pelas lipoproteínas, com a distribuição entre as classes lipoprotéicas, determinada em grande parte pelas propriedades físicas dos carotenóides.

Os carotenóides lipofílicos localizam-se no núcleo das lipoproteínas, enquanto os polares localizam-se na superfície das mesmas.

Os níveis mais elevados de carotenóides nos quilomícrons estão em torno de 4-8 horas após a ingestão de carotenóides, 24-48 horas nas lipoproteínas de baixa densidade (LDL) e 16-48 horas nas lipoproteínas de alta densidade $(\mathrm{HDL})^{15}$.

Em um estudo, realizado por Johnson \& Russell ${ }^{16}$, em que as concentrações plasmáticas de $\beta$-caroteno foram medidas em homens por um período de 10 dias após a administração de uma dose oral de $120 \mathrm{mg}$ de $\beta$-caroteno, foi constatado que o nível plasmático de $\beta$-caroteno elevou-se 6 horas após a administração da dose, chegando ao pico após 24 horas e retornando ao nível basal após 7 dias.

De acordo com os autores, a elevação inicial de $\beta$-caroteno corresponde à elevação do conteúdo deste nos quilomícrons, lipoproteínas de muito baixa densidade (VLDL) e de densidade intermediária (IDL). A captação intestinal está relacionada com a elevação inicial da concentração plasmática de $\beta$-caroteno, enquanto o fígado está relacionado com as elevações posteriores. A transferência de $\beta$-caroteno pode ocorrer entre todas as lipoproteínas.

\section{Clivagem enzimática}

O $\beta$-caroteno é convertido a retinol através da ação da 15-15' $\beta$-caroteno dioxigenase. Olson ${ }^{17}$ relata que esta enzima citossólica requer um detergente e oxigênio molecular, necessita de grupos sulfidrilas livres, contém, provavelmente, ferro ou cobre e apresenta $K_{M}=1-10 \mu m o l ~ e ~ p H$ ótimo= 7,5-8,5.

A clivagem enzimática dos carotenóides ocorre principalmente na mucosa intestinal, embora a enzima possa atuar em outros tecidos, como o fígado, e ao que se sabe, a atividade enzimática na mucosa intestinal depende do nível de proteína da dieta ${ }^{18}$.

Em vertebrados, a clivagem simétrica (central) versus a assimétrica do $\beta$-caroteno na biossíntese de vitamina $A$ e seus derivados é um assunto que tem gerado controvérsias. Em um estudo, Kiefer et al. ${ }^{19}$ identificaram e caracterizaram a catálise oxidativa assimétrica da provitamina A de uma enzima, constatando que em vertebrados existem tanto as clivagens simétricas como as assimétricas dos carotenos, revelando a grande complexidade do metabolismo dos carotenóides.

A clivagem central divide o $\beta$-caroteno na dupla ligação central (15-15') e o produto resultante é o retinal, que pode ser convertido de forma reversível a retinol (vitamina $A$ ) e irreversível a ácido retinóico. Na clivagem assimétrica são formados $\beta$-apocarotenais, que podem ser convertidos a retinal (Figura 3).

Gessler et al. ${ }^{20}$ constataram que radicais livres resultantes da peroxidação lipídica inibem a reação de conversão do $\beta$-caroteno em vitamina A, promovida pela $15-15^{\prime} \beta$-caroteno dioxigenase. A utilização de inibidores de enzimas oxidativas e antioxidantes propicia a proteção da enzima, favorecendo conversão do $\beta$-carotenol na forma ativa da vitamina $A$. 


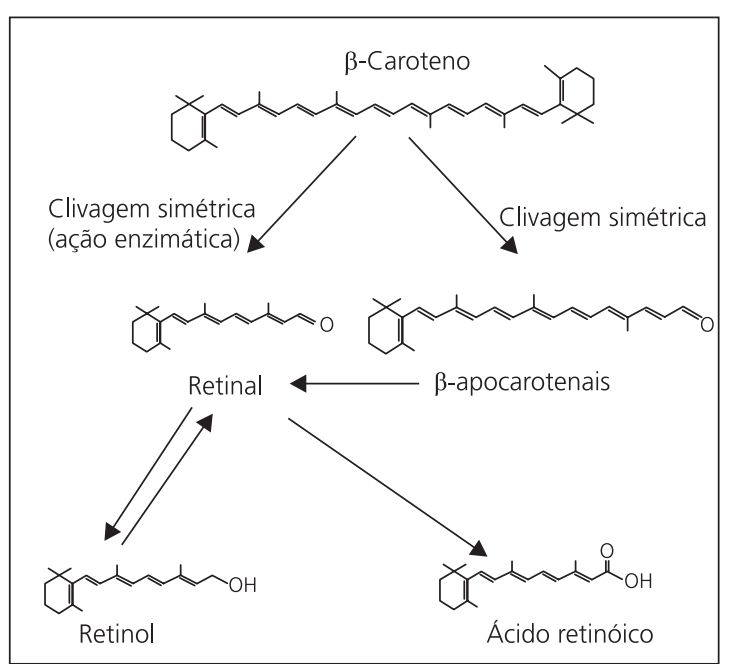

Figura 3. Clivagem simétrica e assimétrica do $\beta$-caroteno.

\section{Biodisponibilidade}

A biodisponibilidade se define como a fração de um determinado nutriente, no caso carotenóides, que pode ser aproveitada pelo organismo.

Ao mencionar biodisponibilidade de carotenóides, outros dois termos importantes são amplamente utilizados na literatura: bioconversão e bioeficácia. Bioconversão é a proporção biodisponível de carotenóides convertidos a retinol, enquanto bioeficácia é a eficiência com a qual os carotenóides ingeridos são absorvidos e convertidos em retinol. Não raramente, os três termos se confundem e, muitas vezes, o termo biodisponibilidade envolve tanto a bioconversão como a bioeficácia.

As informações científicas acerca da biodisponibilidade de carotenóides baseiam-se, principalmente, na determinação dos níveis séricos, plasmáticos ou das frações lipoprotéicas após a ingestão desses. Outros métodos de determinação da biodisponibilidade dos carotenóides também são utilizados, como o método de balanço, pelo do qual o conteúdo de carotenóides ingeridos é medido nas fezes, medida dos carotenóides radiativos na linfa ou estudos cinéticos usando carotenóides isotopicamente marcados.

A biodisponibilidade dos carotenóides é variável e difícil de avaliar. Segundo Brubacher \&
Weiser ${ }^{21}$, a taxa de absorção ou transformação decresce linearmente, de modo inverso ao logaritmo de ingestão. Isso significa que a absorção ou transformação é regulada por um mecanismo que pode ser descrito pela equação de Michaelis-Menten. Essa queda de potência, com o aumento da ingestão, pode ser considerada como um mecanismo natural de regulação, que evita a intoxicação do organismo por essa vitamina. A questão é se existe um mecanismo semelhante nos humanos.

Em termos gerais, os carotenóides são menos biodisponíveis que a vitamina A pré-formada porque estão ligados à matriz dos vegetais, os requerimentos para a absorção intestinal são superiores aos da vitamina $A$ e ainda devem ser enzimaticamente clivados e armazenados como vitamina A ou caroteno em vários tecidos ${ }^{17}$.

\section{Fatores influentes (Slamenghi)}

Um conjunto de fatores exerce influência na biodisponibilidade dos carotenóides, fatores esses que são citados na literatura com a "mnemônica" SLAMENGHI: Species of carotenoids (tipos de carotenóides), molecular Linkage (ligação molecular), A Amount of carotenoids consumed in a meal (quantidade de carotenóides consumidos em uma refeição), Matrix in which the carotenoid is incorporated (matriz na qual os carotenóides são incorporados), Effectors of absorption and bioconversion (efetores de absorção e bioconversão), Nutrient status of the host (estado nutricional do indivíduo), Genetic factors (fatores genéticos), Host-related factors (fatores inerentes ao indivíduo), and mathematical Interactions (interações matemáticas) ${ }^{4}$.

Quanto aos tipos de carotenóides, sabe-se que a configuração natural dos carotenóides nas plantas é o all-trans isômero. Como são compostos altamente insaturados, os carotenóides são susceptíveis a isomerização e oxidação durante o processamento e armazenamento dos alimentos. A isomerização dos trans-carotenóides a 
cis-carotenóides, promovida por acidez, aquecimento e exposição à luz, diminui tanto a coloração como a atividade da vitamina $A$ dos carotenóides ${ }^{22}$.

A quantidade de cis isômeros, formada durante o aquecimento, está relacionada com a severidade e extensão do tratamento térmico. Entretanto, pesquisas sugerem que a absorção de carotenóides provenientes de vegetais crus é inferior à de vegetais cozidos. Em estudo, realizado por Stahl \& Sies $^{23}$, foi constatado que a captação de licopeno em indivíduos adultos é superior em suco de tomate processado (aquecido por 1 hora) em relação à que ocorre em suco não processado (mantido à temperatura ambiente) e observou-se ainda que dos diferentes isômeros geométricos (all- trans, 9- cis e 15-cis), os cis isômeros foram melhor absorvidos.

You et al. ${ }^{24}$ concluíram que ocorre uma significante isomerização cis-trans do 9-cis- $\beta$ -caroteno antes do processo de absorção. Após a administração de uma única dose de 9 -cis- $\beta$ -caroteno $\left({ }^{13} \mathrm{C}\right.$-marcado) para humanos, mais de $95 \%$ do ${ }^{13} \mathrm{C}$-marcado plasmático do trans- $\beta$ -caroteno e do retinol eram provenientes do 9-cis- $\beta$-caroteno ( ${ }^{13} \mathrm{C}$-marcado).

No que diz respeito à ligação molecular, existem poucos dados acerca do efeito da esterificação na biodisponibilidade. Os ésteres de carotenóides parecem ser mais biodiponíveis que os que não estão na forma esterificada ${ }^{4}$. Ésteres de luteína e $\beta$-criptoxantina são comuns em frutas e verduras.

Van Vliet et al. ${ }^{25}$ constataram que em ratos alimentados com dietas com concentração baixa, normal ou elevada em palmitato de retinol (120 $R E, 1200$ RE e 12,000 RE por kg, respectivamente) suplementadas ou não com $50 \mathrm{mg} \beta$-caroteno, o fator de conversão do $\beta$-caroteno para os ratos alimentados com dieta elevada em vitamina $A$ era de 9:1 e de 4:1 para os ratos alimentados com dieta normal ou baixa em vitamina $A$ e que a clivagem intestinal de $\beta$-caroteno é mais elevada em ratos com deficiência de vitamina $A$ que em ratos alimentados com elevada concentração, tanto de vitamina A como de $\beta$-caroteno.
Os carotenóides são absorvidos de forma similar aos lipídios, entretanto existem nutrientes que ao serem ingeridos com os carotenóides interferem no processo de absorção e metabolismo. Borel et al. ${ }^{26}$ constataram que a resposta quilomícron $\beta$-caroteno é consideravelmente menor quando o $\beta$-caroteno é absorvido com triglicerídios de cadeia média (TCM) que quando absorvido com os triglicerídios de cadeia longa (TCL). Vários fatores estão relacionados à ingestão de gordura e aproveitamento de carotenóides, tais como: tipo e fonte de gordura ingerida, quantidade, propriedades físico-químicas e fonte de carotenóides, parasitoses intestinais, faixa etária e estado nutricional do indivíduo.

Dimitrov et al. ${ }^{27}$ constataram que a absorção de $\beta$-caroteno é afetada pela concentração de gordura da dieta. Ao receberem uma dieta hiperlipídica, indivíduos saudáveis apresentaram significante elevação na concentração plasmática de $\beta$-caroteno quando comparados aos indivíduos que receberam uma dieta hipolipídica.

A partir de um estudo, em que os níveis séricos de 12 indivíduos foram avaliados após a administração de dose única de 120mg de $\beta$-caroteno em indivíduos normais, Tang et al. ${ }^{28}$ concluíram que as concentrações séricas de $\beta$-caroteno são mais elevadas em $\mathrm{pH}$ estomacal baixo $(\mathrm{pH}=1,3 \pm 0,1)$ que em elevado $\mathrm{pH}$ $(\mathrm{pH}=6,4 \pm 0,3)$, demonstrando que além dos nutrientes, a acidez interfere no metabolismo do $\beta$-caroteno.

Uma pesquisa realizada por Brown et al. ${ }^{29}$ confirmou que a resposta plasmática do $\beta$-caroteno puro em homens normais é superior àquela obtida do $\beta$-caroteno contido em vegetais (cenoura), quando ingerido na mesma quantidade. Os autores também constataram que cada indivíduo exibe um perfil plasmático estável e característico. A identificação de indivíduos com problemas de absorção sugere que os níveis plasmáticos de carotenóides podem não corresponder à ingestão. Em duas pesquisas similares Micozzi et al. ${ }^{30} \mathrm{e}$ Bulux et al. ${ }^{31}$ também constataram uma menor biodisponibilidade do $\beta$-caroteno consumido em 
vegetais quando comparado ao $\beta$-caroteno puro consumido em cápsulas. Em estudo recente, Thurmann et al. ${ }^{32}$ concluíram que a biodisponibilidade de $\beta$-caroteno em indivíduos que haviam consumido bebida com $\beta$-caroteno na forma de suco de cenoura era inferior à apresentada após o consumo da bebida contendo $\beta$-caroteno em pó.

Os resultados obtidos por estudo realizado por Rock \& Swendseid ${ }^{33}$ indicaram um efeito inibitório da pectina, o que poderia justificar os reduzidos níveis plasmáticos de $\beta$-caroteno em humanos após a ingestão de alimentos ricos em carotenóides, quando comparados a doses equivalentes de suplementos de $\beta$-caroteno.

Estudos referentes à atividade de vitamina A dos carotenóides em vegetais vêm sendo realizados. Em uma pesquisa em que foram acompanhadas crianças da Indonésia, De Pee et al. ${ }^{34}$ concluíram que frutas são mais eficazes na elevação das concentrações séricas de retinol e $\beta$-caroteno que verduras verde-escuras. Tang et al. ${ }^{35}$ concluíram que crianças chinesas alimentadas com vegetais verdes e amarelos mantiveram os níveis séricos de retinol. Em estudo recente, Edwards et al. ${ }^{36}$ constataram que o consumo de suco de melancia elevou as concentrações plasmáticas, tanto de licopeno como de $\beta$-caroteno em indivíduos adultos.

No intuito de avaliar a eficácia dos carotenóides séricos como biomarcadores do consumo de frutas e verduras, Van Kappel et al. ${ }^{37}$ concluíram que uma única medida sérica de $\beta$-caroteno, $\alpha$-caroteno e luteína permite classificar indivíduos de acordo com seus níveis séricos usuais, entretanto a correlação entre as concentrações séricas e o consumo estimado de frutas e verduras é moderada e deve ser utilizados com precaução como biomarcadores da ingestão de vegetais.

A biodisponibilidade de carotenóides em vegetais é variável. Van Het Hof et al. ${ }^{38} \mathrm{com}$ pararam a biodisponibilidade da luteína e do $\beta$-caroteno em vegetais e constataram que a luteína é cinco vezes mais biodisponível.
A luteína é uma molécula lipofílica, porém é mais polar que o $\beta$-caroteno, conseqüentemente pode ser mais facilmente incorporada nas porções externas das micelas lipídicas no trato gastrointestinal e pode ser mais facilmente captada pelas membranas dos enterócitos e, eventualmente, pelos quilomícrons, o que proporciona a elevação da biodisponibilidade ${ }^{39}$. Em estudo realizado com homens saudáveis, Johnson et al. ${ }^{40}$ constataram que a ingestão de dose combinada de $\beta$-caroteno e licopeno não afeta a absorção do $\beta$-caroteno, mas eleva a do licopeno. Através da administração de doses orais de luteína e $\beta$-caroteno, Kostic et al ${ }^{41}$ demonstraram que os carotenóides competem durante a absorção intestinal, o metabolismo e o clearance plasmático, embora as respostas dos indivíduos possam diferir marcadamente.

Em um estudo, em que foi avaliada a variabilidade da conversão do $\beta$-caroteno à vitamina $\mathrm{A}$ em mulheres, Lin et al. ${ }^{42}$ concluíram que a absorção e a conversão do $\beta$-caroteno à vitamina $A$ variadas contribuem para respostas variadas ao consumo deste carotenóide. Os fatores genéticos individuais interferem nestas respostas ${ }^{43}$.

A partir de um estudo realizado por Ribaya-Mercado et al. ${ }^{44}$, em que foram avaliadas crianças filipinas com idade entre 7 e 13 anos, concluiu-se que a bioconversão de carotenóides à vitamina $A$ variou de forma inversa ao status de vitamina A. A melhora do status após a intervenção é altamente influenciada pelo total de armazenamento corpóreo de vitamina $A$, e é pouco ou negativamente influenciada pelo retinol sérico.

As interações matemáticas constituem um dos fatores SLAMENGHI e se referem à diferença entre o efeito observado quando dois fatores exercem uma função conjuntamente e o produto dos efeitos observados isoladamente. Não existem, ainda, dados que possibilitem uma estimativa das interações matemáticas.

\section{Fontes de carotenóides}

Existem vários alimentos que são fontes de carotenóides, como a abóbora, cenoura, 
manga, batata doce, espinafre, mostarda, couve, entre outros. Entretanto, o buriti (Mauritia vinifera) e o dendê (Elaeis guineensis), que são frutos de palmeiras, se destacam como as fontes mais ricas de provitamina A encontradas no Brasil22.

Em um estudo em que foi avaliada a atividade de vitamina A do buriti, Mariath et al..$^{45}$ concluíram que ocorreu reversão de xeroftalmia e elevação de reservas hepáticas da vitamina, sugerindo a possível utilização do buriti em programas de combate à deficiência de vitamina $\mathrm{A}$.

O óleo de dendê vem sendo amplamente estudado e é inquestionável a sua potencialidade como fonte de carotenóides no combate à hipovitaminose $\mathrm{A}^{46-48}$.

O enriquecimento de alimentos com fontes naturais de provitamina $A$, como os óleos de buriti e dendê, poderia ser uma alternativa eficiente para reverter o problema da hipovitaminose A no Brasil. O óleo de soja ou a margarina, que são amplamente consumidos pela população, poderiam ser os veículos utilizados.

O tucumã (Astrocaryum aculeatum), a macaúba (Acrocomia aculeata), a pupunha (Bactris gasipaes) e o pequi (Caryocar brasiliense) são ainda outras importantes fontes regionais de carotenóides no Brasil.

Yuyama \& Cozzolino ${ }^{49}$ constataram que ratos que consumiram uma ração à base da dieta regional de Manaus, suplementada com a polpa da pupunha cozida e transformada em farinha, apresentaram concentração significativamente maior de vitamina A no fígado $(43,3 \pm 6,5 \mu \mathrm{g} / \mathrm{g})$, quando comparados aos que receberam a dieta não suplementada $(5,5 \pm 1,1 \mu \mathrm{g} / \mathrm{g})$.

De acordo com Graebner et al. ${ }^{50}$, verduras verde-escuras nativos do Brasil (serralha - Sonchus oleraceus, bredo - Amaranthus viridis e taioba - Xanthosoma sagittifolium) são biodisponíveis em ratos. Este resultado corrobora com os anteriormente obtidos por Tang et al..$^{35} \mathrm{e}$ Edwards et al. ${ }^{36}$.

Em pesquisa realizada por Faro ${ }^{51}$ a biodisponibilidade de carotenóides também foi comprovada em ratos que consumiram uma dieta complementada com flocos desidratados de abóbora. O aproveitamento industrial da abóbora como flocos desidratados e a sua utilização em produtos derivados seria um meio eficaz tanto para ajudar a combater a hipovitaminose A como para estimular o cultivo da abóbora, trazendo benefícios tanto para os produtores rurais como para a agroindústria.

Estudos, como os acima citados, demonstram que existem alternativas de aproveitamento de fontes diversas de carotenóides. A forma de administração dessas fontes é fundamental para o sucesso nos programas de combate à deficiência de vitamina A. Um óleo vegetal não refinado, como o de dendê, é uma excelente fonte, uma vez que se encontra livre da barreira de uma matriz vegetal, ou, um produto submetido a um processamento, como no caso da abóbora, que ao ser transformada em flocos possibilita que a ingestão diária de vitamina A seja atingida com uma pequena quantidade do produto.

É importante também levar em consideração fatores fisiopatológicos dos diferentes grupos etários de indivíduos que estão sendo tratados para garantir a eficácia do programa.

A ingestão diária mínima de vitamina $A$, para garantir um nível sérico adequado e prevenir sintomas de deficiência em indivíduos adultos, é de 500 a $600 \mu \mathrm{g}$, em crianças 200 a 300 $\mathrm{gg}$, gestantes $550 \mu \mathrm{g}$ e lactantes $900 \mu^{5}$.

Os atuais fatores de conversão de carotenóides em retinol ${ }^{5}$, superiores aos antigos fatores ${ }^{7}$, colocam em questionamento a utilização de fontes de carotenóides no combate à hipovitaminose A. Entretanto tais fatores propostos se baseiam em populações sadias. Ao que se sabe a bioconversão de carotenóides é maior em indivíduos com carência de vitamina $A^{25,44}$. Dessa forma, se esperam melhores respostas às suplementações com fontes de carotenóides em grupos de indivíduos com carência da vitamina.

Atualmente existe um banco de dados sobre composição de carotenóides em diversos 
alimentos brasileiros ${ }^{52,53}$, o que minimiza a falta de exatidão ao utilizar tabelas gerais de composição de alimentos ${ }^{54}$, em especial em inquéritos dietéticos que possibilitam a avaliação do estado nutricional de indivíduos e programas de intervenção.

A falta de informação da população acerca das fontes de carotenóides é fato que deve ser levado em consideração. Programas de educação nutricional poderiam facilitar o processo de aprendizagem da população acerca dessas fontes, o que funcionaria também como um fator colaborador no combate à hipovitaminose A. Em estudo realizado por Faber et al. ${ }^{55}$ constatou-se que um programa que envolvia o cultivo de verduras verde-escuras e amarelas, atenção primária à saúde e educação nutricional em uma comunidade rural, proporcionou a elevação dos níveis séricos de retinol de crianças com idade entre dois e cinco anos na África do Sul.

\section{O N C L U S Ã O}

Embora os atuais fatores de conversão de carotenóides em retinol sejam superiores aos fatores anteriores, existem pontos que devem ser considerados:

- Os fatores de conversão se baseiam em populações sadias e, ao que se sabe, a bioconversão de carotenóides é maior em indivíduos com carência de vitamina A.

- Atualmente existe um banco de dados sobre composição de carotenóides em diversos alimentos, o que minimiza a falta de exatidão ao utilizar tabelas gerais de composição de alimentos.

- A falta de informação da população acerca das fontes de carotenóides é um fator limitante para um melhor aproveitamento dessas fontes como alternativa contra a hipovitaminose A. Programas de educação nutricional poderiam facilitar o processo de aprendizagem da população.

- O Brasil apresenta uma enorme variedade de fontes de carotenóides. A forma de administração dessas fontes e os alimentos veículos são fundamentais para o sucesso nos programas de combate à deficiência de vitamina A. Além disso, fatores fisiopatológicos e a ingestão diária recomendada de vitamina $\mathrm{A}$ dos diferentes grupos etários de indivíduos que estão sendo tratados também devem ser levados em consideração.

- Os fatores SLAMENGHI exercem influência na biodisponibilidade dos carotenóides, entretanto existem alternativas que possibilitam minimizar determinadas limitações decorrentes destes.

Ao ter conhecimento acerca dos itens acima citados, pode-se concluir que é possível e viável a utilização de fontes de carotenóides no combate à hipovitaminose $A$ em países em desenvolvimento, como o Brasil.

\section{REFERÊ NCIAS}

1. Olson JA. Metabolism and function of vitamin A. Federation Proceedings. 1969; 28(5):1670-7.

2. Ramalho RA, Flores H, Saunders C. Hipovitaminose A no Brasil: um problema de saúde pública. Rev Panam Salud Publica. 2002; 12(2):117-22.

3. World Health Organization. Global prevalence of vitamin A deficiency (WHO/NUT/95.3). Geneva; 1995.

4. West CE, Castenmiller JJM. Quantification of "SLAMENGHI" factors for carotenoid bioavailability and bioconversion. Int I Vit Nutr Res. 1998; 68(6):371-7.

5. National Academy of Sciences. Dietary Reference intakes for vitamin A, vitamin $\mathrm{K}$, arsenic, boron, chromium, copper, iodine, iron, manganese, molybdenum, nickel, silicon, vanadium, and zinc. Washington (DC); 2001.

6. International Vitamin A Consultative Group. Conversion factors for vitamin A and Carotenoids. ILSI Research Foundation; 2002.

7. National Academy of Sciences. Recommended dietary allowances. 8th ed. Washington (DC); 1974

8. Kim MK, Ahn SH, Lee-Kim YC. Relationship of serum $\alpha$-tocopherol, carotenoids and retinol with the risk of breast cancer. Nutr Res. 2001; 21: 797-809. 
9. Ziegler RG. Vegetables, fruits, and carotenoids and the risk of cancer. Am J Clin Nutr. 1991; 53(1 Suppl):2515-95.

10. Olson JA. Carotenoids and human health. Arch Latinoam Nutr. 1999; 49(1-S):7-11.

11. Osganian SK, Stampfer MJ, Rimm E, Spiegelman D, Manson JE, Willett WC. Dietary carotenoids and risk of coronary artery disease in women. Am J Clin Nutr. 2003; 77(6):1390-9.

12. Gale $C R$, Ashurst $H E$, Powers $H J$, Martyn $C N$. Antioxidant vitamin status and carotid atherosclerosis in the elderly. Am J Clin Nutr. 2001; 74(3):402-8.

13. Landrum JT, Bone RA. Lutein, zeaxanthin, and the macular pigment. Arch Biochem Biophys. 2001; 385(1):28-40.

14. Snodderly DM. Evidence for protection against age-related macular degeneration by carotenoids and antioxidants vitamins. Am J Clin Nutr. 1995; 62(6 Suppl):1448S-61S.

15. Cornwell DG, Kruger FA. Studies on the absorption of beta-carotene and the distribution of total carotenoid in human serum lipoproteins after oral administration. J Lipid Research 1962; 3 (1):65-70.

16. Johnson EJ, Russell RM. Distribution of orally administered beta-carotene among lipoproteins in healthy men. Am J Clin Nutr. 1992; 56(1): 128-35.

17. Olson JA. Bioavailability of carotenoids. Arch Latinoam Nutr. 1999; 49(1-S):21-5.

18. Gronowska-Senger A, Wolf G. Effect of dietary protein on the enzyme from rat and human intestine which converts b-carotene to retinal. J Nutr. 1970; 100:300-8.

19. Kiefer C, Hessel S, Lampert JM, Vogt K, Lederer $M O$, Breithaupt $D E$, et al. Identification and characterization of a mammalian enzyme catalyzing the asymmetric oxidative cleavage of provitamin A. J Biol Chem. 2001; 276 (27): 14110-16.

20. Gessler NN, Gomboeva SB, Shumaev KB, Bykhovskii VY, Lankin VZ. Free radical lipid peroxidation inhibits enzymatic conversion of $\beta$-carotene into vitamin A. Bull Exp Biol Med. 2001; 131(5):451-3.

21. Brubacher $G B$, Weiser $H$. The vitamin $A$ activity of beta-carotene. Int J Vit Nutr Res. 1985; 55(1):515.

22. Rodriguez-Amaya DB. Carotenoids and food preparation: the retention of provitamin $A$ carotenoids in prepared, processed, and stored foods. John Snow, Inc/OMNI Project; 1997. 88p.

23. Stahl W, Sies H. Uptake of lycopene and its geometrical isomers is greater from heat-processed than from unprocessed tomato juice in humans. J Nutr. 1992; 122(11):2161-6.

24. You CS, Parker RS, Goodman KJ, Swanson JE, Corso TN. Evidence of cis-trans isomerization of 9-cis- $\beta$-carotene during absorption in humans. Am J Clin Nutr. 1996; 64(2):177-83.

25. van Vliet T, van Vlissingen MF, van Schaik F, van Den Berg, H. $\beta$-Carotene absorption and cleavage in rats is affected by the vitamin $A$ concentration of the diet. J Nutr. 1996; 126(2):499-508.

26. Borel P, Tyssandier V, Mekki N, Grolier P, Rochette $Y$, Alexandre-Gouabau MC, et al. Chylomicron $\beta$-carotene and retinyl palmitate responses are dramatically diminished when men ingest $\beta$-carotene with medium-chain rather than long-chain triglycerides. J Nutr. 1998; 128(8): 1361-67.

27. Dimitrov NV, Meyer C, Werey DE, Chenoweth W, Michelakis A, Malone $W$, et al. Bioavailability of beta-carotene in humans. Am J Clin Nutr. 1988; 48(2):298-304.

28. Tang G, Serfaty-Lacrosniere C, Camilo ME, Russell RM. Gastric acidity influences the blood response to a $\beta$-carotene dose in humans. Am J Clin Nutr. 1996; 64(4):622-6.

29. Brown ED, Micozzi MS, Craft NE, Bieri JG, Beecher $\mathrm{G}$, Edwards BK, et al. Plasma carotenoids in normal men after a single ingestion of vegetables or purified $\beta$-carotene. Am J Clin Nutr. 1989; 49(6): 1258-65.

30. Micozzi MS, Brown ED, Edward BK, Bieri JG, Taylor PR, Khachik F, et al. Plasma carotenoid response to chronic intake of selected foods and $\beta$-carotene supplements in men. Am J Clin Nutr. 1992; 55(6): 1120-5.

31. Bulux J, Quan de Serrano V, Giuliano A, Perez R, Lopez $C Y$, Rivera $C$, et al. Plasma response of children to short-term chronic $\beta$-carotene supplementation. Am J Clin Nutr. 1994; 59(6): 1369-75.

32. Thurmann PA, Steffen $V$, Zwernemann C, Acbischer CP, Cohn W, Wendt G, et al. Plasma concentration response to drinks containing beta-carotene as carrot juice or formulated as a water dispersible powder. Eur J Nutr. 2002; 41(5):228-35.

33. Rock CL, Swendseid ME. Plasma $\beta$-carotene response in humans after meals supplemented with dietary pectin. Am J Clin Nutr. 1992; 55(1): 96-9.

34. De Pee $S$, West $C E$, Permaesih D, Martuti S, Muhilal, Hautvast JG. Orange fruit is more effective than are dark-green, leafy vegetables in increasing serum concentrations of retinol and $\beta$-carotene in schoolchildren in Indonesia. Am J Clin Nutr. 1998; 68(5):1058-67. 
35. Tang G, Gu X, Hu S, Xu Q, Quin J, Dolnikowski GG, et al. Green and yellow vegetables can maintain body stores of vitamin A in Chinese children. Am J Clin Nutr. 1999; 70(6):1069-76.

36. Edwards AJ, Vinyard BT, Wiley ER, Brown ED Collins JK, Perkins-Veazie $P$, et al. Consumption of watermelon juice increases plasma concentrations of lycopene ans $\beta$-carotene in humans. J Nutr. 2003; 133(4):1043-50.

37. van Kappel $A L$, Steghens JP, Zeleniuch-Jacquotte A, Chajes V, Toniolo P, Riboli E. Serum carotenoids as biomarkers of fruit and vegetables consumption in the New York women's health study. Public Health Nutr. 2001; 4(3):829-35.

38. van Het Hof KH, Brower IA, West CE, Haddeman E, Skegers-Theunissen RP, van Dusseldop $M$, et al. Bioavailability of lutein from vegetables is 5 times higher than that of $\beta$-carotene. Am J Clin Nutr. 1999; 70(2):261-8.

39. Erdman JW Jr. Variable bioavailability of carotenoids from vegetables. Am J Clin Nutr. 1999; 70(2):179-80.

40. Johnson EJ, Qin J, Krinsky NI, Russell RM. Ingestion by men of a combined dose of $\beta$-carotene and lycopene does not affect the absorption of $\beta$-carotene but improves that of lycopene. J Nutr. 1997; 127(9):1833-7.

41. Kostic D, White WS, Olson JA. Intestinal absorption, serum clearance, and interactions between lutein and $\beta$-carotene when administered to human adults in separate or combined oral doses. Am J Clin Nutr. 1995; 62(3):604-10.

42. Lin Y, Dueker SR, Burri BJ, Neidlinger TR, Clifford AJ. Variability of the conversion of $\beta$-carotene to vitamin $A$ in women measured by using a double-tracer study design. Am J Clin Nutr. 2000; 71(6):1545-54.

43. Bonn, D. International consortium SN(i)Ps away at individuality. Lancet. 1999; 353(9165): 1684.

44. Ribaya-Mercado JD, Solon FS, Solon MA, Cabal-Barza MA, Perfecto CS, Tang G, et al. Bioconversion of plant carotenoids to vitamin $A$ in Filipino school-aged children varies inversely with vitamin A status. Am J Clin Nutr. 2000; 72(2):455-65.
45. Mariath JG, Lima MC, Santos LM. Vitamin A activity of buriti (Mauritia vinifera Mart) and its effectiveness in the treatment and prevention of xerophthalmia. Am J Clin Nutr. 1989; 49(5): 849-53.

46. Canfield LM, Kaminsky RG. Red palm oil in the maternal diet improves the vitamin A status of lactating mothers and their infants. Food Nut Bull. 2000; 21:144-8.

47. Mahapatra S, Manorama R. The protective effect of red palm oil in comparison with massive vitamin A dose in combating vitamin A deficiency in Orissa, Índia. Asia Pacific J Clin Nutr. 1997; 6:246-50.

48. Manorama R, Rukmini C. Effect of processing on $\beta$-carotene retention in crude palm oil and its products. Food Chemistry. 1991; 42(3):253-64.

49. Yuyama LKO, Cozzolino SMF. Efeito da suplementação com pupunha como fonte de vitamina A em dieta: estudo em ratos. Rev Saúde Pública. 1996; 30(1):61-6.

50. Graebner IT, Siqueira EMA, Arruda SF, Souza EMT. Carotenoids from native brazilian dark-green vegetables are bioavailable: a study in rats. Nutr Res. 2004; 24(8):671-9.

51. Faro ZP. Aproveitamento industrial da polpa de abóbora [tese]. Recife: Universidade Federal de Pernambuco; 2001.

52. Rodriguez-Amaya DB. Assessment of the provitamin A contents of foods: the brazilian experience. J Food Comp Anal. 1996; 9:196-230.

53. Rodriguez-Amaya DB. Latin american food sources of carotenoids. Arch Latinoam Nutr. 1999; 49(3 Suppl 1):74S-84S

54. Rodriguez-Amaya DB. Some considerations in generating carotenoid data for food composition tables. J Food Comp Anal. 2000; 13:641-47.

55. Faber M, Phungula MAS, Venter SL, Dhansay MA, Benade AJS. Home gardens focusing on the production of yellow and dark-green leafy vegetables increase the serum retinol concentrations of 2-5-y-old children in South Africa. Am J Clin Nutr. 2002; 76(5):1048-54.

Recebido em: 12/3/2004

Versão final reapresentada em: 13/6/2005 Aprovado em: 27/7/2005 